\title{
Penggunaan tongue scraper dan kebersihan gigi dan mulut setelah penyuluhan pada anak Panti Asuhan Ashabul Kahfi Makassar \\ Using tounge scraper and oral-dental hygiene after counseling at children of orphanage Ashabul Kahfi Makassar
}

\author{
${ }^{1}$ Idham, ${ }^{1}$ Rifaat Nurrahma, ${ }^{2}$ Rasmidar Samad \\ ${ }^{1}$ Dokter gigi \\ ${ }^{2}$ Bagian Ilmu Kesehatan Gigi Masyarakat Fakultas Kedokteran Gigi Universitas Hasanuddin \\ Makassar, Indonesia
}

\begin{abstract}
Tongue cleaning is a simple and quick procedure to eliminate organisms and debris on tongue. Tongue cleaning can be performed by using a tongue scraper. This study was conducted to determine the correlation between the index of OHI-S and tongue coating, and explain the knowledge of oral hygiene and a tongue scraper tongue at an orphanage in Makassar. Subjects were children of orphanage Ashabul Kahfi, who attend and agree to all the procedures. Dental hygiene assessed by OHI-S index and examination of the tongue by tongue coating index. A total of 24 boys and 16 girls were given questionnaires before and after counseling. The results showed no significant correlation between the two indices $(p=0.382)$. Distribution of the questionnaire answers showed increased correct answers after giving counseling. However, based on the level of education and gender, showed no significant differences in knowledge regarding the cleanliness of the tongue and a tongue scraper $(p=0.858, p=0.486)$. Significant differences were also seen in the comparison group who use and do not use a tongue scraper. It was concluded that there was no significant correlation between OHI-S index and tongue coating, but counseling would increase knowledge of the child orphanage Ashabul Kahfi although there was no difference in knowledge regarding the cleanliness of the tongue and a tongue scraper based on education level and gender.
\end{abstract}

Keywords: OHI-S index, index of tongue coating, counseling, tongue hygienic, tongue scraper

\begin{abstract}
ABSTRAK
Pembersihan lidah adalah suatu prosedur sederhana dan cepat yang membantu menghilangkan organisma dan debris pada lidah. Pembersihan lidah dapat dilakukan dengan menggunakan tongue scraper. Penelitian ini dilakukan untuk mengetahui korelasi antara indeks OHI-S dan tongue coating, dan menjelaskan pengetahuan mengenai kebersihan lidah dan tongue scraper pada anak panti asuhan (PA) di Makassar. Subjek penelitian adalah anak PA Ashabul Kahfi yang berada di tempat pada saat penelitian dan bersedia mengikuti prosedur penelitian. Kebersihan gigi dinilai indeks OHI-S dan pemeriksaan lidah berdasarkan indeks tongue coating. Sebanyak 24 laki-laki dan 16 perempuan diberi kuesioner sebelum dan setelah penyuluhan. Hasilnya menunjukkan tidak ada hubungan yang signifikan antara kedua indeks $(\mathrm{p}=0,382)$. Distribusi jawaban kuesioner menunjukkan peningkatan jawaban benar setelah pemberian penyuluhan. Namun, berdasarkan tingkat pendidikan dan jenis kelamin, menunjukkan perbedaan yang tidak signifikan pengetahuan mengenai kebersihan lidah dan tongue scraper $(\mathrm{p}=0,858, \mathrm{p}=0,486)$. Perbedaan yang tidak signifikan juga terlihat pada perbandingan kelompok yang menggunakan dan tidak menggunakan tongue scraper. Disimpulkan bahwa tidak ada korelasi yang bermakna antara indeks OHI-S dan tongue coating. Akan tetapi pemberian penyuluhan mampu meningkatkan pengetahuan anak PA Ashabul Kahfi, meskipun tidak ada perbedaan pengetahuan mengenai kebersihan lidah dan tongue scraper dilihat dari tingkat pendidikan dan jenis kelamin.
\end{abstract}

Kata kunci: indeks OHI-S, indeks tongue coating, penyuluhan, kebersihan lidah, tongue scraper

Koresponden: Idham, drgidham@yahoo.com

\section{PENDAHULUAN}

Oral hygiene status merupakan suatu metode yang digunakan dalam menilai status kesehatan mulut seseorang. Status kebersihan mulut dinilai berdasarkan ada tidaknya kalkulus dan debris pada gigi yang telah ditentukan sebelumnya. ${ }^{1}$

Oral hygiene $(\mathrm{OH})$ sangat penting peranannya untuk mengontrol kebersihan gigi dan gingiva,serta penting untuk menjaga kesehatan di sekitar mulut. Membersihkan gigi minimal dua kali sehari dengan pasta gigi ber-flouride dan penggunaan dental floss; juga penting unuk membersihkan daerah lain dari mulut, utamanya lidah. ${ }^{2}$

Saat ini, masyarakat memiliki keterbatasan informasi mengenai sikap dan pengetahuan dalam menjaga $\mathrm{OH}$. Untuk mencapai kesehatan yang baik, makapemeliharaankesehatan gigi dan rongga mulut pada masyarakat memerlukan beberapa hal penting, antara lain motivasi dalam menjaga kebersihan gigi dan mulut, pemeriksaan berkala gigi dan mulut ke dokter gigi, dan pemahaman individu mengenai cara memelihara kesehatan gigi dan mulutnya. 
Bagian dorsum lidah termasuk jaringan lunak, yang seluruh permukaannya terdiri dari papila yang memiliki area permukaan yang luas. Berbagai organisme ditemukan berkolonisasi pada dorsum lidah. Oleh karena itu, pembersihan lidah sangatlah penting, mengingat permukaan dorsum lidah adalah tempat utama bagi pertumbuhan mikroorganisme, khususnya bakteri anaerob, sehingga pembersihan lidah selain dapat mengurangi halitosis juga dapat mengeliminasi sebagian bakteri fakultatif anaerob dan obligat anaerob yang berperan dalam penyakit periodontal. $^{3}$

Berdasarkan hal tersebut di atas,perlu diketahui pengetahuan masyarakat mengenai kebersihan lidah dan tongue scraper, khususnya anak panti asuhan Ashabul Kahfi. Selain tentunya, berharap mampu memberikan informasi ilmiah mengenai efektivitas penggunaan tongue scraper terhadap kebersihan lidah.

\section{BAHAN DAN METODE}

Untuk mengetahui kebersihan gigi digunakan indeks OHI-S, sedangkankebersihan lidah digunakan indeks tongue coating. Dalam penelitian ini juga dilihat pengetahuan mengenai kebersihan lidah dan tongue scraper, menggunakan kuesioner. Penelitian observasi deskriptif dengan desain cross-sectional study menggunakan subjek 24 laki-laki dan 16 perempuan yang anak panti asuhan Ashabul Kahfi dan bersedia mengikuti prosedur penelitian.Mereka diminta untuk mengisi kuesioner ${ }^{4}$ sebelum dan sesudah penyuluhan. Analisis data menggunakan program SPSS versi 12,0 dengan penyajian data dalam bentuk tabel. Uji statistik yang dipakai adalah uji-t, ANOVA dan Spearman rho dengan nilai $\mathrm{p}<0,05$.

\section{HASIL}

\section{Hubungan kebersihan lidah dengan OHI-S}

Tabel 1 memperlihatkan distribusi beberapa karakteristik subjek penelitian, yaitu jenis kelamin, tingkat pendidikan, tongue coating sebelum dan setelah pemakaian tongue scraper.Dari total sampel 40, subjek dengan jenis kelamin laki-laki lebih banyak dibandingkan perempuan, yaitu sebesar 24 orang $(60 \%)$.Berdasarkan tingkat pendidikan paling banyak ditemukan tingkat pendidikan SMP, yaitu sebesar 26 orang $(65 \%)$. Ditinjau dari tingkat kebersihan mulut yang dinilai berdasarkan OHI-S diperoleh yang terbanyak dengan kategori sedang sebanyak 26 orang (65\%). Dari pengukuran tongue coating sebelumpenggunaan tongue scraper diperoleh jumlah terbanyak ditemukan subjek dengan indeks tongue coating 3 , yaitu 18 orang.Sedangkan setelah penggunaan tongue scraper, jumlah terbanyak ditemukan subjek dengan indeks tongue coating 2 .

Tabel 2 dengan menggunakan uji Spearman's, menunjukkan hubungan indeks OHI-S subjek dengan indeks tongue coating sebelum penggunaan tongue scraper diperoleh $p=0,382$. Hal ini menunjukkan tidak ada hubungan yang signifikan antara indeks OHIS dengan indeks tongue coating.

Tabel 1 Distribusi karakteristik subjek penelitian

\begin{tabular}{cccc}
\hline \multicolumn{2}{c}{ Variabel } & \multicolumn{3}{c}{ Frekuensi N (\%) } & Mean \pm SD \\
\hline \multirow{2}{*}{ Jenis kelamin } & Laki-laki & $24(60)$ & $1,29 \pm 0,65$ \\
& Perempuan & $16(40)$ & $1,90 \pm 0,70$ \\
\hline \multirow{2}{*}{ Pendidikan } & SMP & $26(65)$ & $1,61 \pm 0,77$ \\
& SMA & $14(35)$ & $1,42 \pm 0,65$ \\
\hline \multirow{2}{*}{ OHIS } & Baik & $14(35)$ & $0,77 \pm 0,28$ \\
& Sedang & $25(65)$ & $1,95 \pm 0,53$ \\
\hline \multirow{2}{*}{ Tongue coating } & 1 & $5(12,5)$ & $1,60 \pm 0,80$ \\
sebelum & 2 & $17(42,5)$ & $1,41 \pm 0,73$ \\
& 3 & $18(45)$ & $1,65 \pm 0,73$ \\
\hline \multirow{2}{*}{ Tongue coating } & 0 & $6(15)$ & $1,16 \pm 0,49$ \\
sesudah & 1 & $15(37,5)$ & $1,38 \pm 0,83$ \\
& 2 & $19(47,5)$ & $1,62 \pm 0,64$ \\
Total & 3 & $3(7,5)$ & $2,20 \pm 0,53$ \\
\hline
\end{tabular}

Tabel 2 Korelasi indeks tongue coating dan indeks OHI-S

\begin{tabular}{ccccc}
\hline \multirow{2}{*}{ Status OHI-S } & \multicolumn{4}{c}{ Tongue coating sebelum (\%) } \\
\cline { 2 - 5 } & 1 & 2 & 3 & $\mathrm{P}$ \\
\hline Baik & $2(5,0)$ & $7(17,5)$ & $5(12,5)$ & \multirow{2}{*}{0,382} \\
Sedang & $3(7,5)$ & $10(24,5)$ & $6(32,5)$ & \\
\hline Total & $5(12,5)$ & $17(43,0)$ & $18(45,0)$ & \\
\hline Uji Spearman's Rho $p<0,05$ &
\end{tabular}


Tabel 3 Distribusi jawaban kuesioner pengetahuan mengenai tongue scraper sebelum dan sesudah penyuluhan

\begin{tabular}{|c|c|c|c|c|c|c|}
\hline \multirow{2}{*}{ Pertanyaan } & \multicolumn{3}{|c|}{ Sebelum Penyuluhan $(\mathrm{n}=40)$} & \multicolumn{3}{|c|}{ Sesudah Penyuluhan $(n=40)$} \\
\hline & Benar & Salah & $p$ & Benar & Salah & $P$ \\
\hline $\begin{array}{l}\text { 1. Menurut anda, pentingkah membersihkan lidah? } \\
\text { (Ya*/Tidak/Tidak tahu). }\end{array}$ & 15 & 25 & 0,154 & 17 & 23 & 0,430 \\
\hline $\begin{array}{l}\text { 2. Apakah kebersihan lidah berpengaruh terhadap } \\
\text { kesehatan tubuh? (Ya*/Tidak/Tidak tahu). }\end{array}$ & 27 & 13 & 0,038 & 40 & 0 & 0,000 \\
\hline $\begin{array}{l}\text { 3. Berapa kali sehari seharusnya membersihkan lidah } \\
\text { dalam sehari? }\left(1 \mathrm{X} / 2 \mathrm{X}^{*} / 3 \mathrm{X} \text { atau lebih }\right.\end{array}$ & 16 & 24 & 0,268 & 34 & 6 & 0,000 \\
\hline $\begin{array}{l}\text { 4. Kapan seharusnya membersihkan lidah? (Setelah } \\
\text { sikat gigi*/Setelah makan/setelah makan makanan } \\
\text { manis). }\end{array}$ & 26 & 14 & 0,081 & 38 & 2 & 0,000 \\
\hline $\begin{array}{l}\text { 5. Apa tujuan membersihkan lidah? (Membersihkan } \\
\text { lidah dan mencegah bau mulut*/Mengurangi biaya } \\
\text { perawatan gigi/ Mencegah luka pada mulut) }\end{array}$ & 39 & 1 & 0,000 & 39 & 1 & 0,000 \\
\hline $\begin{array}{l}\text { 6. Apa pengertian debris lidah? (Penumpukan kotoran } \\
\text { lunak yang melekat pada lidah*/Penumpukan } \\
\text { kotoran keras yang melekat pada lidah/Perubahan } \\
\text { warna pada lidah). }\end{array}$ & 29 & 11 & 0,006 & 39 & 1 & 0,000 \\
\hline $\begin{array}{l}\text { 7. Apa penyebab penebalan debris lidah? (Kekurangan } \\
\text { kalsium/Merokok, penggunaan antibiotik dalam }\end{array}$ & & & & & & \\
\hline $\begin{array}{l}\text { waktu yang lama, penyakit sistemik*/Penyakit gusi } \\
\text { akibat kesalahan cara menyikat gigi) }\end{array}$ & 15 & 25 & 0,154 & 35 & 5 & 0,000 \\
\hline $\begin{array}{l}\text { 8. Bagaimana cara mencegah penebalan debris lidah? } \\
\text { (Menyikat lidah secara teratur dengan sikat lidah*/ } \\
\text { Konsumsi suplemen kalsium/Mengurangi konsumsi } \\
\text { Makanan). }\end{array}$ & 38 & 2 & 0,000 & 39 & 1 & 0,000 \\
\hline $\begin{array}{l}\text { 9. Apa yang sebaiknya digunakan untuk } \\
\text { membersihkan lidah? (Jari tangan/Sikat lidah*/ } \\
\text { Bubuk pembersih gigi). }\end{array}$ & 39 & 1 & 0,000 & 40 & 1 & 0,000 \\
\hline $\begin{array}{l}\text { 10. Bagaimana metode membersihkan lidah? (1 arah*/ } \\
2 \text { arah/Arah berputar) }\end{array}$ & 20 & 20 & 1,000 & 40 & 0 & 0,000 \\
\hline $\begin{array}{l}\text { 11. Berapa tarikan sebaiknya dilakukan sewaktu } \\
\text { membersihkan lidah? (1 X/2-3 X*/4 X atau lebih). }\end{array}$ & 16 & 24 & 0,268 & 25 & 15 & 0,154 \\
\hline $\begin{array}{l}\text { 12. Apakah anda menggunakan alat pembersih mulut } \\
\text { lainnya? (Ya*/Tidak/Tidak tahu) }\end{array}$ & 8 & 32 & 0,000 & 10 & 30 & 0,002 \\
\hline $\begin{array}{l}\text { 13. Jika anda ke dokter gigi, apa alasan anda ke dokter } \\
\text { gigi? (Pemeriksaan rutin*/Disuruh orang tua/Tidak } \\
\text { pernah ke dokter gigi) }\end{array}$ & 11 & 29 & 0,006 & 12 & 28 & 0,017 \\
\hline $\begin{array}{l}\text { 14. Apakah anda merawat lidah sama seperti anda } \\
\text { merawat gigi? (Ya*/Tidak/Tidak pernah) }\end{array}$ & 11 & 29 & 0,006 & 19 & 21 & 0,875 \\
\hline $\begin{array}{l}\text { 15. Menurut anda, apakah perlu pergi ke dokter gigi } \\
\text { secara teratur? (Ya*/Tidak/Tidak tahu) }\end{array}$ & 24 & 16 & 0,268 & 24 & 16 & 0,268 \\
\hline
\end{tabular}

Anak panti diberikan kuesioner sebanyak dua kali.Mereka diinstruksikan menjawab 15 pertanyaan pada kuesioneruntuk mengukur pengetahuan mereka mengenai tongue scraper. Setiappertanyaan bernilai, "1" untuk jawaban benar dan "0" untuk jawaban salah (Tabel 3).

Selain itu,dalam penelitian inijuga dapat dilihat rasio pengetahuan anak panti yang menggunakan dan tidak menggunakan tongue scraper (Tabel 4).

Tingkat pendidikan anak panti berbeda-beda, namun mereka hidup dalam pola pengajaran yang sama dengan kualitas pengajar yang sama.Rata-rata pendidikan anak panti yang ditempuh adalah SMP dan SMA (Tabel 5).

\section{PEMBAHASAN}

Pada hasil penelitian ini nampak tidak ada hubungan yang signifikan antara indeks OHI-S subjek dengan indeks tongue coating sebelum dan setelah penggunaan tongue scraper, hubungannya tidak signifikan. Beberapa studi menunjukkanbahwa jika penggunaan pembersih lidah dikombinasi dengan metode $\mathrm{OH}$ lain, dapat menurunkan pembentukan plak dental. 
Tabel 4 Perbandingan pengetahuan anak panti yang menggunakan dengan yang tidak menggunakan tongue scraper sebelum dan sesudah penyuluhan (uji-t, $\mathrm{p}<0,05$ )

\begin{tabular}{llccccc}
\hline & & $\mathrm{n}$ & Mean $\pm \mathrm{SD}$ & $P$ & Peningkatan Jawaban Benar & $P$ \\
\hline \multirow{2}{*}{ Menggunakan } & Sebelum & 40 & $55,67 \pm 13,80$ & 0,000 & $19,50 \pm 11,53$ & 0,697 \\
& Sesudah & 40 & $75,17 \pm 11,50$ & & & \\
\multirow{2}{*}{ Tidak menggunakan } & Sebelum & 32 & $55,83 \pm 15,95$ & 0,000 & $19,38 \pm 11,65$ & \\
& Sesudah & 32 & $75,21 \pm 14,29$ & & & \\
\hline
\end{tabular}

Tabel 5 Perbandingan pengetahuan anak panti berdasarkan tingkat pendidikan dan jenis kelamin sebelum dan sesudah penyuluhan (uji Anova, $\mathrm{p}<0,05$ )

\begin{tabular}{lcccccc} 
& \multicolumn{7}{c}{ Sebelum Penyuluhan } & \multicolumn{2}{c}{ Sesudah Penyuluhan } \\
& $\mathrm{n}$ & Mean \pm SD & $p$ & Mean \pm SD & $p$ & $p$ \\
\hline Tingkat Pendidikan & & & & & & \\
SMP & 26 & $54,36 \pm 13,16$ & 0,421 & $74,10 \pm 12,55$ & 0.432 & 0,858 \\
SMA & 14 & $58,10 \pm 11,53$ & & $77,14 \pm 9,32$ & & \\
Jenis Kelamin & & & & & & \\
Laki-laki & 24 & $53,33 \pm 14,58$ & 0,194 & $73,89 \pm 12,11$ & 0.396 & \\
Perempuan & 16 & $59,17 \pm 12,14$ & & $77,08 \pm 10,60$ & & \\
\hline
\end{tabular}

Badersten dkk mendapatkan bahwa tidak terdapat perbedaan akumulasi plak antara 4 hari pemakaian pembersih lidah dan 4 hari tanpa prosedur $\mathrm{OH}$. Ketika sikat gigi dibandingkan dengan kombinasi pembersih lidah selama 1 minggu, tidak ada perbedaan akumulasi plak. ${ }^{2}$ Banyak faktor yang mungkin saja menjadi penyebabnya, misalnya kebanyakan orang cenderung lebih sering menyikat gigi tanpa disertai penyikatan lidah dan menganggap pembersihan lidah merupakan hal yang kurang penting.

Lapus mengatakan bahwa menurut Survei Kesehatan Gigi Nasional pada tahun 2005 dan 2006 di 17 wilayah Filipina, menemukan anak 15 tahun mengalami perdarahan gingiva dan atau kalkulus yang disebabkan karena kebiasaan kebersihan mulut, khususnya tidak menyikat gigi secara teratur yang disertai dengan bau mulut karena bertumpuknya kotoran pada lidah. ${ }^{5}$

Pada tabel 3, diperlihatkan distribusi jawaban kuesioner untuk pertanyaan pengetahuan mengenai kebersihan lidah dan tongue scraper yang diberikan sebelum dan sesudah penyuluhan. Meningkatnya jawaban benar terjadi pada beberapa pertanyaan. Setelah penyuluhan diberikan, nampak perbedaan yang signifikan antara kedua kelompok jawaban. Hal ini membuktikan bahwa penyuluhan mampu meningkatkan pengetahuan anak-anak dan harus dipertimbangkan dalam upaya meningkatkan derajat kesehatan gigi dan mulut.

Penelitian mengenai pengaruh penyuluhan kesehatan gigidan mulut yang dilakukan pada siswa kelas IV dan V SDK Santa Maria Ponorogo menunjukkan ada pengaruh penyuluhan kesehatan gigi dan mulut dengan metode demonstrasi terhadap sikap anak dalam memelihara kesehatan gigi dan mulut,dan adanya perbedaan efektivitas antara sikap anak untuk memelihara kesehatan gigi-mulut yang tidakmendapat penyuluhan dengan sikap anak dalam memeliharakesehatan gigi danmulut yang mendapat penyuluhan. ${ }^{6}$

Perbandingan pengetahuan mengenai tongue scraper antara anakpanti yang menggunakan dengan yang tidak menggunakan pembersih, sebelum dan sesudah penyuluhan dapat dilihat pada tabel 4 . Dengan menggunakan uji- $t$ nampak tidak adanya perbedaan yang signifikan antara kedua kelompok $(p=0,697)$. Namun, bila dibandingkan antara nilai sebelum dan sesudah penyuluhan pada kelompok menggunakan maupun tidak menggunakan tongue scraper terlihat perbedaan yang signifikan dengan nilai $p=0,000$. Dari tabel ini terlihat bahwa yang mempengaruhi pengetahuan anak panti adalah penyuluhan. Meskipun penyuluhan yang dilakukan sangat sederhana, dengan langsung menggunakan alat peraga untuk mencapai materi penyuluhan, penyuluhan yang santai diselingi sedikit permainan ternyata mampu memberikan hasil lebih optimal.

Penyuluhan adalah proses belajar secara non formal kepada sekelompokmasyarakat tertentu.Dari penyuluhan kesehatan gigi dan mulut diharapkan terciptanya suatu pengertian yang baik mengenai kesehatan gigi dan mulut. Terdapat beberapa jenis penyuluhan kesehatan gigi dan mulut, namun cara yang paling sering digunakan adalah penyuluhan kesehatan gigi dan mulut dengan metode ceramah dan penyuluhan kesehatan gigi dan mulut dengan metode bermain. ${ }^{7}$

Berger dkk,menyatakan selain permainan dapat melintasi berbagai golongan usia, permainan juga dapatmempengaruhipenampilananak-anak di muka umum menjadi lebih nyaman sehingga menjadi penolongdalampenyuluhan kesehatangigi dan mulut. 
Sedangkan hasil penelitian Castilo dkk di Durango, Mexico kepada 300 anak usia 8-11 tahun yang diambil secara acak menunjukkan bahwa permainan merupakan suatu pilihan dalampenyuluhan kesehatan gigi dan mulut pada tingkat sekolah dasar.Pernyataan tersebut diperkuat oleh Brandley,bahwa proses belajar lebih aktifdan lebih menyenangkanjika digabungkan denganpermainan.Hasilnya adalah penyuluhan yang merupakan suatu proses belajar lebih berpengaruh dalammeningkatkan pengetahuan jika digabungkan dengan permainan. ${ }^{7}$

Terdapat penelitian lain tentang perbandingan pembelajaran menggunakan media komunikasi yang menunjukkan bahwa terdapat peningkatan pengetahuan dan perilaku kesehatan gigi dan mulut setelah dental healtheducation menggunakan metode visual dibanding dengan metode audiovisual. Hal tersebut disebabkan metode visual terutama menggunakan mata dalam praktek.Berdasarkan teori efektivitas komunikasi, sekitar $80 \%$ pengetahuan seseorangdiperolehdari aktivitas visual. Keberhasilan komunikasi didominasi faktor visual $55 \%$, diikuti faktor audio $36 \%$, lalu faktor perasaan $15 \%$, faktor komunikasi verbal $7 \%$, dan faktor sentuhan $1 \%{ }^{8}$
Pada tabel 5 nampak tidak ada hubungan yang signifikan antara tingkat pendidikan dan jenis kelamin dengan pengetahuan anak panti mengenai tongue scraper. Hal ini nampak pada nilai $p$ untuk setiap kategori pendidikan dan jenis kelamin. Meskipun demikian, seharusnya semakin tinggi tingkat pendidikan semakin jauh daya tangkap pemahaman orang tersebut sehingga mempengaruhi pengetahuannya.

Dari pembahasan mengenai penggunaan tongue scraper dan kebersihan gigi dan mulut setelah penyuluhan pada anak Panti Asuhan Ashabul Kahfi Makassar, disimpulkan bahwa tidak ada korelasi yang bermakna antara indeks OHI-S dan indeks tongue coating. Selain itu, pemberian penyuluhan mampu meningkatkan pengetahuan anak panti. Hal inidapatmenjadipertimbangan penting dalam upaya peningkatan derajat kesehatan gigi dan mulut. Berdasarkan tingkat pendidikan dan jenis kelamin terlihat tidak ada perbedaan signifikan pengetahuan mengenai kebersihan lidah dan tongue scraper. Pemahaman pengetahuan bertolak pada metode penyuluhan yang diberikan dan metode demonstrasi/ bermain merupakan alternatif pilihan yang tepat.

\section{DAFTAR PUSTAKA}

1. Danser MM, Gomez SM, van der Weijeden GA. Tongue coating and tongue brushing: a literature review. Int J Dent Hygiene 2003; 1: 151-8. [Internet]. Available from: http://www.halitosis-research.com/Tongue_Coating_and_ Brushing_Literature_Review.html. Accessed on Desember 3, 2009.

2. Greene JC, Vermillion JR. Institute for algorithmic medicine the oral hygiene index: a method for classifying oral hygiene status. J Am Dent Assoc 1960; 61: 172-9. [Internet]. Avalable from: http:/www_Active_ch9_ch9.01_ ch9.01.08.aspx.htm. Published on 2007. Accessed on December 10 December 2009

3. Prijono E, Dewi W, Puspa TK. Efektivitas pembersihan lidah secara mekanis menggunakan tongue scraper terhadap jumlah populasi bakteri anaerob lidah. J Persatuan Dokter Gigi Indonesia. Edisi khusus 2007. p.95-100.

4. Sharda AJ, Shetty S. A comparative study of oral health knowledge, attitude and behavior of first and final year dental students of Udaipur City, Rajasthan. [Internet]. Available from : www.johcd.org. Published on October 2009. Accessed on December 17 2009. J Oral Health Comm Dent 2008; 2(3):46-54.

5. Khalid A, Essam A. The effect tongue scraper in patient with caries and periodontal disease. J Odonto-Stomatologie Tropicale 2005 [Internet]. Available from : http:/www.nlmdental.org/pdf/scraper/n-109. Accessed on 7 Desember 2009.

6. Widyawati YR. Pengaruh penyuluhan kesehatan gigi dan mulut (metode demonstrasi) terhadap sikap anak dalam memelihara kesehatan gigi dan mulut pada siswa kelas IV dan V di SDK Santa Maria Ponorogo. [Internet]. Available from: http://skripsistikes.wordpress.com/2009/05/03/ikpiii107/. Published on May 3 2009. Accessed on December 17 2009. Research Report.

7. Rusli M, Gondhoyoewono T. Pengaruh metode bermain terhadap penyuluhan kesehatan gigi dan mulut. [Internet]. Available from: http://dhammasena.6forum.biz/fkg-hall-f39/pengaruh-metode-bermain-terhadap-penyuluhankesehatan-gigi-dan-mulut-t494.htm. Published on June 8 2009. Accessed on December 17 2009. J Persatuan Dokter gigi Indonesia Online.

8. Ariestiana YY. Comparing knowledge and atitude of children related to dental and oral health after dental health education (DHE) using visual aid and audiovisual aid. Prosiding Temu Ilmiah Tahun Emas FKG Unpad; 2009. p. $131-40$. 